\title{
Microtomography-based numerical simulations of heat transfer and fluid flow through -SiC open-cell foams for catalysis
}

DOI:

10.1016/j.cattod.2015.12.012

\section{Document Version}

Accepted author manuscript

Link to publication record in Manchester Research Explorer

Citation for published version (APA):

Fan, X., Ou, X., Xing, F., Turley, G. A., Denissenko, P., Williams, M. A., Batail, N., Pham, C., \& Lapkin, A. A. (2016). Microtomography-based numerical simulations of heat transfer and fluid flow through -SiC open-cell foams for catalysis. Catalysis Today, 278(2), 350-360. https://doi.org/10.1016/j.cattod.2015.12.012

\section{Published in:}

Catalysis Today

\section{Citing this paper}

Please note that where the full-text provided on Manchester Research Explorer is the Author Accepted Manuscript or Proof version this may differ from the final Published version. If citing, it is advised that you check and use the publisher's definitive version.

\section{General rights}

Copyright and moral rights for the publications made accessible in the Research Explorer are retained by the authors and/or other copyright owners and it is a condition of accessing publications that users recognise and abide by the legal requirements associated with these rights.

\section{Takedown policy}

If you believe that this document breaches copyright please refer to the University of Manchester's Takedown Procedures [http://man.ac.uk/04Y6Bo] or contact uml.scholarlycommunications@manchester.ac.uk providing relevant details, so we can investigate your claim.

\section{OPEN ACCESS}




\title{
Microtomography-based numerical simulations of heat transfer and fluid flow through $\beta$-SiC open-cell foams for catalysis
}

\author{
Xiaolei Fan ${ }^{\mathrm{a}, *}$, Xiaoxia Ou ${ }^{\mathrm{a}}$, Fei Xing ${ }^{\mathrm{b}}$, Glen A. Turley ${ }^{\mathrm{c}}$, Petr Denissenko ${ }^{\mathrm{d}}$, \\ Mark A. Williams ${ }^{\mathrm{c}}$, Nelly Batail ${ }^{\mathrm{e}}$, Charlotte Pham ${ }^{\mathrm{e}}$, Alexei A. Lapkin ${ }^{\mathrm{f}, *}$ \\ a School of Chemical Engineering and Analytical Science, The University of Manchester, Oxford Road, Manchester M13 9PL, United Kingdom \\ b School of Aerospace Engineering, Xiamen University, Xiamen, 361005 Fujian, China \\ c Product Evaluation Technologies Group, WMG, University of Warwick, Coventry CV4 7AL, United Kingdom \\ d School of Engineering, University of Warwick, Coventry, CV4 7AL, United Kingdom \\ e SICAT SARL, 20 Place des Halles, 67000 Strasbourg, France \\ ${ }^{\mathrm{f}}$ Department of Chemical Engineering and Biotechnology, University of Cambridge, Cambridge CB2 3RA, United Kingdom
}

\section{A R T I C L E I N F O}

\section{Article history:}

Received 16 October 2015

Received in revised form

17 December 2015

Accepted 18 December 2015

Available online $\mathrm{xxx}$

\section{Keywords:}

$\beta$-SiC

Open-cell foam

Finite element analysis (FEA)

Effective thermal conductivity

Computational fluid dynamics (CFD)

Fluid flow

\begin{abstract}
A B S T R A C T
$\beta$-SiC open-cell foams are promising materials for catalytic supports with improved heat and mass transfer at moderate pressure drops. In this work, 3-dimensional (3D) models of a $30 \mathrm{ppi}$ (pores per inch) $\beta$-SiC open-cell foam were generated using X-ray microtomography data. The resulting foam models were then used for finite element analysis (FEA) and computational fluid dynamics (CFD) simulations of heat transfer and fluid flow on the pore-scale. The FEA results demonstrate that (i) the overall effective thermal conductivity from direct simulations is comparable to the results estimated by experimental measurement, and are in the order of $10^{-1} \mathrm{~W} \mathrm{~m}^{-1} \mathrm{~K}^{-1}$ and (ii) thermal transport through fluid-saturated $\beta$-SiC foams depends on the solid-to-fluid conductivity ratio. By employing realistic foam models, pore-scale CFD simulations of fluid flows revealed the microscopic characteristics of laminar flow through open-cell foams. The anisotropic feature of realistic foam models promotes the axial and radial mixing of fluids in and after the foam element. The diffusion coefficient of laminar flow within foams was estimated at $10^{-4} \mathrm{~m}^{2} \mathrm{~s}^{-1}$, which is much larger than the molecular diffusion coefficient in a typical laminar flow in an open channel.
\end{abstract}

(c) 2016 Elsevier B.V. All rights reserved.

\section{Introduction}

Structured reactors and catalysts are promising technologies that may transform conventional chemical processes with a step change [1-3]. Recently, porous SiC-based cellular materials (also known as open-cell foams or sponges based on alpha [4] or beta polytype [5]) stimulated ideas of designing multi-scale porous structured materials for catalytic/chemical applications [4,5]. The $\beta$-SiC foams can be produced by a self-bonding $\beta$-SiC manufacturing process delivering (i) an outstanding mechanical strength (>2 MPa crushing strength) and (ii) a superior chemical resistance in aggressive environments (e.g., BET surface area remains stable after a two-week aging at $293 \mathrm{~K}$ in various aggressive media, such as $40 \mathrm{vol} . \% \mathrm{HF}, 37 \mathrm{vol} . \% \mathrm{HCl}$ and $10 \mathrm{M} \mathrm{NaOH}$ ) [5,6]. Such interesting

\footnotetext{
* Corresponding authors.

E-mail addresses: xiaolei.fan@manchester.ac.uk(X.Fan), aal35@cam.ac.uk (A.A. Lapkin).
}

combinations of mechanical and physical properties of $\beta$-SiC opencell foams make them promising to handle harsh conditions, such as at high temperature and pressure with acidic or basic reaction media, commonly experienced in industrial chemical transformations.

$\mathrm{SiC}$ open-cell foams with random morphology possess high tortuosity with interconnected cells in all directions [7], which can (i) facilitate the axial and radial mixing within the foam matrix and (ii) promote the enhanced heat, mass and momentum transfer [5]. The open structure and fully accessible surface area of $\mathrm{SiC}$ foams also result in low pressure drop, e.g., four times lower than conventional spherical packing [8], and high effective contact surface between the reactant and the active site within the reactor $[5,9,10]$. Furthermore, the presence of a thin silicon oxycarbide $\left(\mathrm{SiO}_{x} \mathrm{C}_{y}\right)$ and silica $\left(\mathrm{SiO}_{2}\right)$ layer on $\beta$-SiC also ensures strong anchoring of the active phases, such as H-ZSM-5 zeolite [9] and cobalt [10], solving the problems encountered with silica or alumina supports [9,11]. All the advantages of $\mathrm{SiC}$ open-cell foams contribute to better catalytic performance in terms of activity and productivity, in comparison 
with other types of reactors such as wall-coated plug-flow reactor or packed-bed reactor. Thus, dimethyl ether yield in methanol dehydration in a fixed bed reactor was only ca. $31 \%$, versus $78 \%$ attained in a structured foam [9]. To date, open-cell SiC foams have been successfully demonstrated as an excellent catalytic support for various reactions: e.g., methanol dehydration to dimethyl ether $[9,12]$, methanol to propylene [4,13], Fischer-Tropsch synthesis $[10,14]$, liquid-phase hydrogenation reactions [15] and steam-free dehydrogenation of ethylbenzene to styrene [16]. Furthermore, large void structure of such foams can maximise the light radiation through the reaction media within a reactor, hence promoting new designs of continuous-flow photocatalytic applications, e.g., photocatalytic wastewater treatment using a $\mathrm{TiO}_{2} / \beta$-SiC foam-structured photoreactor [17-19].

Full characterisation of $\mathrm{SiC}$ foams either at the microscopic or the macroscopic level is essential for better design and operation of novel chemical reactors or processes based on them. Therefore, both experimental and numerical approaches were employed to gain knowledge of hydrodynamic and thermal properties in/of SiC foams and assess their capability of carrying chemical reactions. Edouard and Pham-Huu carried out extensive experimental characterisation of $\beta$-SiC foams, including pressure drop measurements of single phase flow through foams and empirical analyses [20-22], hydrodynamics, including residence time distribution, pressure drop and liquid holdup, and dynamic-static liquid mass transfer of two phases flows (air-water) under co-current flow configurations $[23,24]$, radial liquid dispersion in an upward liquid flow through foams [25] and effective radial heat conductivity of a solid foam packing, wall heat transfer coefficient under fluid flow conditions [26].

However, direct simulation of reactors based on solid foams is more challenging than that of conventional chemical reactors because of the intricate nature of foam structures, the high degree of irregularity and randomness. Therefore, unit cells such as regular pentagonal dodecahedra [27,28], Kelvin cells (the tetrakaidecahedron geometry) [29-31], diamond structures [31] and other idealised geometrical cells $[32,33]$ were proposed for pore-scale investigation of the general effects in idealised foam structures based on unit cells, e.g., modelling mass transfer [27], heat transfer [28] and hydrodynamics within foam-based geometries [29-33]. Simulation works based on abstracted foam models are convenient to extract basic characteristics, in the hope of resembling the ones of real foam structures, for designing applications based on foams. However, foams usually have non-periodic multi-scale structures, characteristic features of foams' natural variations are often lost with such unit cell models, indicating the findings obtained from idealised models may not be reproducible in cases of real foams.

A combination of recent technical and modelling advances enables the implementation of direct numerical simulation of flow in foams using realistic foam models. X-ray microcomputed tomography $(\mu-\mathrm{CT})$ enables to capture and reconstruct the complex structure of porous media in accurate details [34-37]. Thus, simulations with realistic representations of metal opencell foams were carried out using finite element method for the analysis of heat transfer properties of metal foams [34,37-39]. Findings of computational studies can be used to correct empirical correlations for predicting the effective thermal conductivity of foam-based devices [38]. Only few numerical investigations using the microtomography-based modelling and simulation approaches examining the fluid domain within the open-cell structures have been published to date $[34,36,37]$. Such direct modelling and simulations of real foam geometries are particularly beneficial for reducing the demands for experiments and for successful design of chemical processes based on foam materials.

In this work, the microscopic approach based on $\mu$-CT is used to generate models with the preservation of geometrical features. $\mu$ -
CT data are processed using new advanced algorithms and exported in relevant mesh formats for direct numerical analyses. Considering the specific geometry of the foam and fluid domains, the heat transfer and fluid flow simulations on the pore-scale are performed.

\section{Experimental}

\subsection{Materials and method}

$\beta$-SiC open-cell foams were provided by SICAT SARL (France). The materials (30 ppi $\beta$-SiC open-cell foams, bulk density $=360 \mathrm{~g} \mathrm{~cm}^{-1}$, void fraction $=80 \%$ ) were received as disks with a diameter $50 \mathrm{~mm}$, thickness $10 \mathrm{~mm}$, as shown in Fig. 1a. The foam was scanned with a Metris XT H 320 LC Micro-Focus CT system (Nikon Metrology, UK). The CT system consisted of a cone-beam X-ray source, a rotary Table and $2000 \times 2000$ pixel flat panel detector. As with many industrial CT scanners, the source and detector are stationary with the sample being mounted on the rotary Table [40]. The CT scanner was demonstrated to be a useful dimensional metrology tool for tasks of scanning foam materials $[41,42]$. To maximise resolution of the projected radiograph image, the foam was positioned as close to the X-ray source as possible while still ensuring the entire object geometry remained within the field of view of the cone beam X-ray source. The sample was scanned with $225 \mathrm{kV}$ maximum X-ray energy at a detector pixel resolution of $10.024 \mu \mathrm{m}$ in both the horizontal and vertical directions. The sample was rotated through $360^{\circ}$ about the fixed vertical axis of the rotary table, so that the X-rays were able to penetrate the object from all directions. The spatial geometry was then reconstructed using CTPro (Nikon Metrology, UK), yielding a $3 \mathrm{D}$ voxelised representation of the sample, in which the gray value of each of the volume elements represented the X-ray attenuation characteristics of the material within that volume. The resulting images from the scan data were saved in DICOM format (a stack of 2-dimensional (2D) images, corresponding to the scanned 3D object), and then transferred to the SIMPLEWARE ScanIP [43] for processing.

\subsection{Image processing}

Original data contains a large number of pixels, resulting in high memory demands and computational time for model manipulation. Therefore, a downsampling is necessary to reduce the number of pixels contained in the original model. The 75 micron pixel spacing (cubic resampling) was found adequate to lower the resolution as well as to keep the foam geometry well represented. The 'Threshold' segmentation tool (based on values of 40-255) was applied to $2 \mathrm{D}$ images for this purpose. The processed 2D images were then stitched together to render a 3D foam model, corresponding to the original materials. Due to the features of technological process, the struts are porous themselves (Fig. 2) possessing fine, below the micro-CT resolution, features in the form of thin bridges and sharp-cornered cavities. In order to facilitate the subsequent mesh generation, Cavity fill filter was used to fill the void space within the struts of the 3D foam model, since $\beta$-SiC was found to be porous. Recursive Gaussian filter with 75 micron Gaussian sigma was employed to reduce images noise, such as small spikes around pores. The 3D model was then processed by the Island removal filter and Floodfill segmentation tool to remove any unconnected regions or islands. At this point, the processed 3D model of $\beta$-SiC foam, as shown in Fig. 1b, is ready for fluid domain extraction, FEA and CFD mesh generation in the SIMPLEWARE ScanFE [43].

Due to memory limitations in ScanIP and ScanFE, only small sub-models from the 3D foam model (Fig. 1b) were considered in this work. Sub-models, i.e., cubes with size $10 \times 10 \times 10 \mathrm{~mm}$, were 
(a)

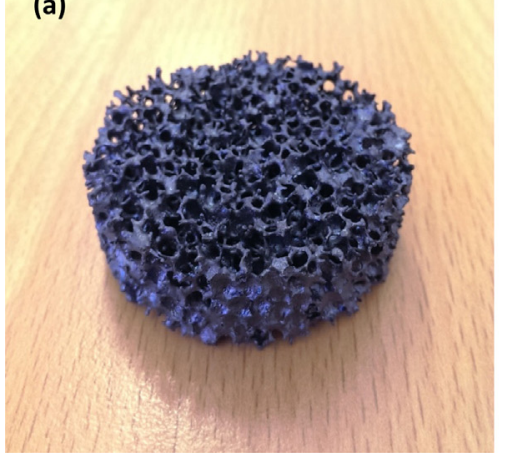

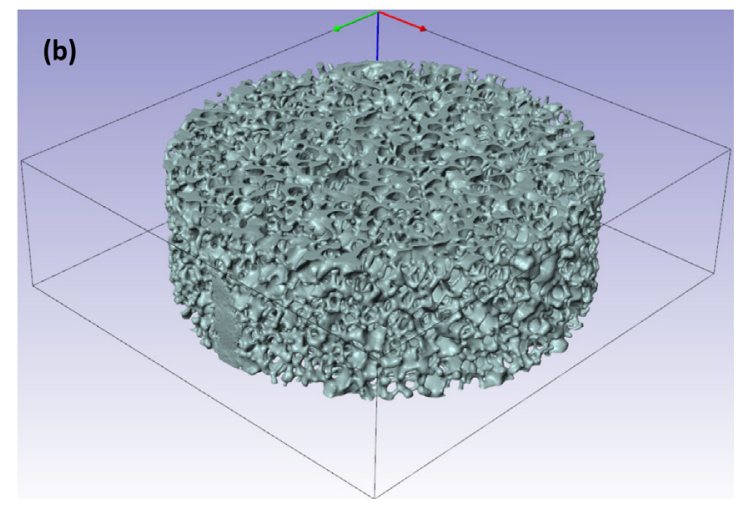

Fig. 1. (a) A $30 \mathrm{ppi} \beta$-SiC foam disk as received and (b) 3D rendering of a $30 \mathrm{ppi} \beta$-SiC foam disk (by SIMPLEWARE).
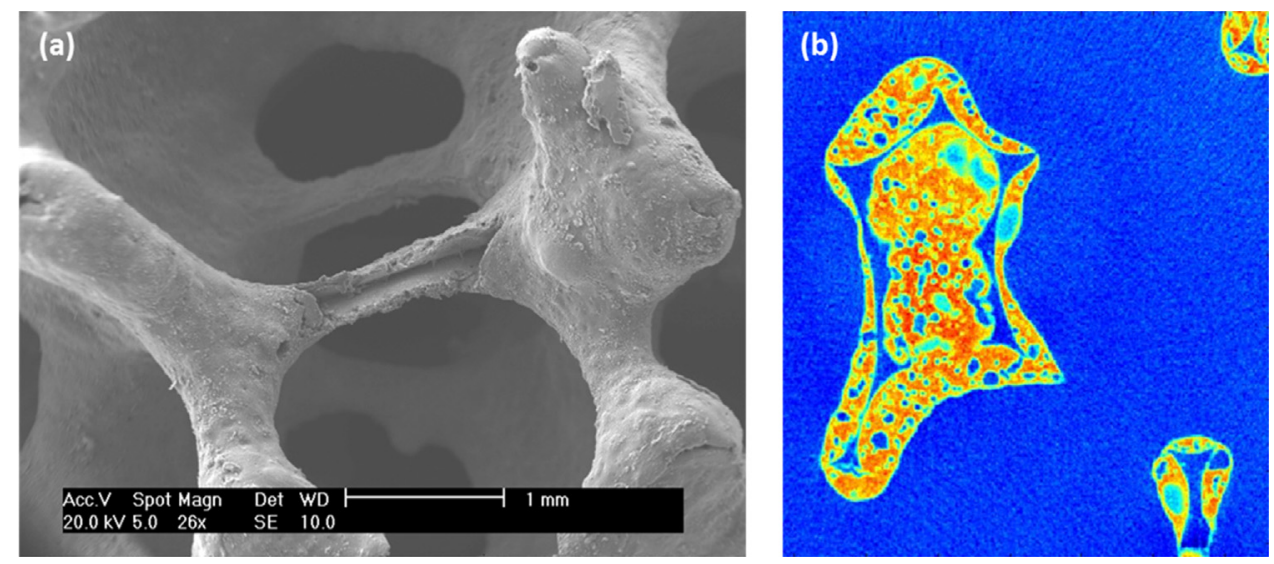

Fig. 2. Actual structure of $\beta$-SiC foam struts. (a) SEM image and (b) cross-sectional image produced by $\mu$-CT.

cut off from different regions of the original 3D foam disk model (Fig. 1b, the operation was performed in the SIMPLEWARE). The Invert Boolean in the SIMPLEWARE ScanIP operation was applied to the resulting cubic foam models to extract relevant fluid domains that are contained within the cubic models. The fluid models are then assembled with inlet and outlet fluid domains in ${ }^{+}$CAD module and exported (in ScanIP format) for mesh generation.

\subsection{Mesh generation}

The foam models were meshed using ${ }^{+} \mathrm{FE}$ Free meshing algorithm in SIMPLEWARE ${ }^{+} \mathrm{FE}$ module. The ${ }^{+}$FE Free meshing algorithm is a tetrahedral mesher with the main purpose of providing a better transition between small and large elements to help reducing the mesh size. It is most suited to geometries where there is a need to preserve small features, e.g., foams and fluid within foams, whilst decimating the mesh elsewhere, e.g., the outlet fluid domain [43]. Minimum/maximum edge lengths and surface/internal change rates were specified accordingly to optimise and further reduce the number of cells in the meshes. Additional quality improvement was enabled to improve the quality of meshes and the lowest (worst) in-out aspect ratio was kept smaller than 0.20 for all the meshes generated. The relevant meshes of foam and fluid models are shown in Fig. 3. The generated meshes were then exported in relevant formats for direct simulation campaigns in ABAQUS FEA and ANSYS FLUENT.

\section{Numerical modelling}

The finite element analysis (FEA) of heat conduction through $\beta$-SiC foams was performed using ABAQUS FEA (v. 6.12). Uncou- pled heat transfer analysis was used to model the solid body heat conduction with constant conductivity and radiation boundary conditions. The temperature field in an uncoupled heat transfer problem was solved without consideration of mechanical aspects, i.e., stress and deformation. The basic energy balance is shown as Eq. (1) [44]:

$\int{ }_{v} \rho \dot{U} d V=\int{ }_{s} \vec{q} d S+\int{ }_{v} r d V$

where $V$ is the volume of the model, with surface area $S ; \rho$ is the density of the material; $\dot{U}$ is the material time rate of the internal energy; $\vec{q}$ is the heat flux flowing into the body; and $r$ is the heat supplied externally into the body per unit volume.

It is assumed that thermal and mechanical problems are uncoupled in the sense that $\dot{U}$ depends on temperature of the material only, and $\vec{q}$ and $r$ do not depend on the strains or displacements of the body. For simplicity, a Lagrangian description is assumed, so 'volume' and 'surface' mean the volume and surface in the reference configuration of an original geometry model. Heat conduction through the foam is assumed to be governed by Fourier law:

$\vec{q}=-\lambda \frac{\partial T}{\partial x}$

where $\vec{q}$ is the local heat flux ( $\mathrm{W} \mathrm{m}^{-2}$ ); $\lambda$ is the material's conductivity $\left(\mathrm{W} \mathrm{m}^{-1} \mathrm{~K}^{-1}\right) ; x$ is position. The substrate of the material is assumed to be isotropic and, therefore, thermal conductivity, $k$, is treated any edges any edges any edges any edges as a constant in the current simulation.

The heat conduction simulations through $\beta$-SiC foams were performed with the following boundary conditions (Fig. 3a): prescribed high temperature on one surface $\left(T_{\text {hot }}\right)$ and room 

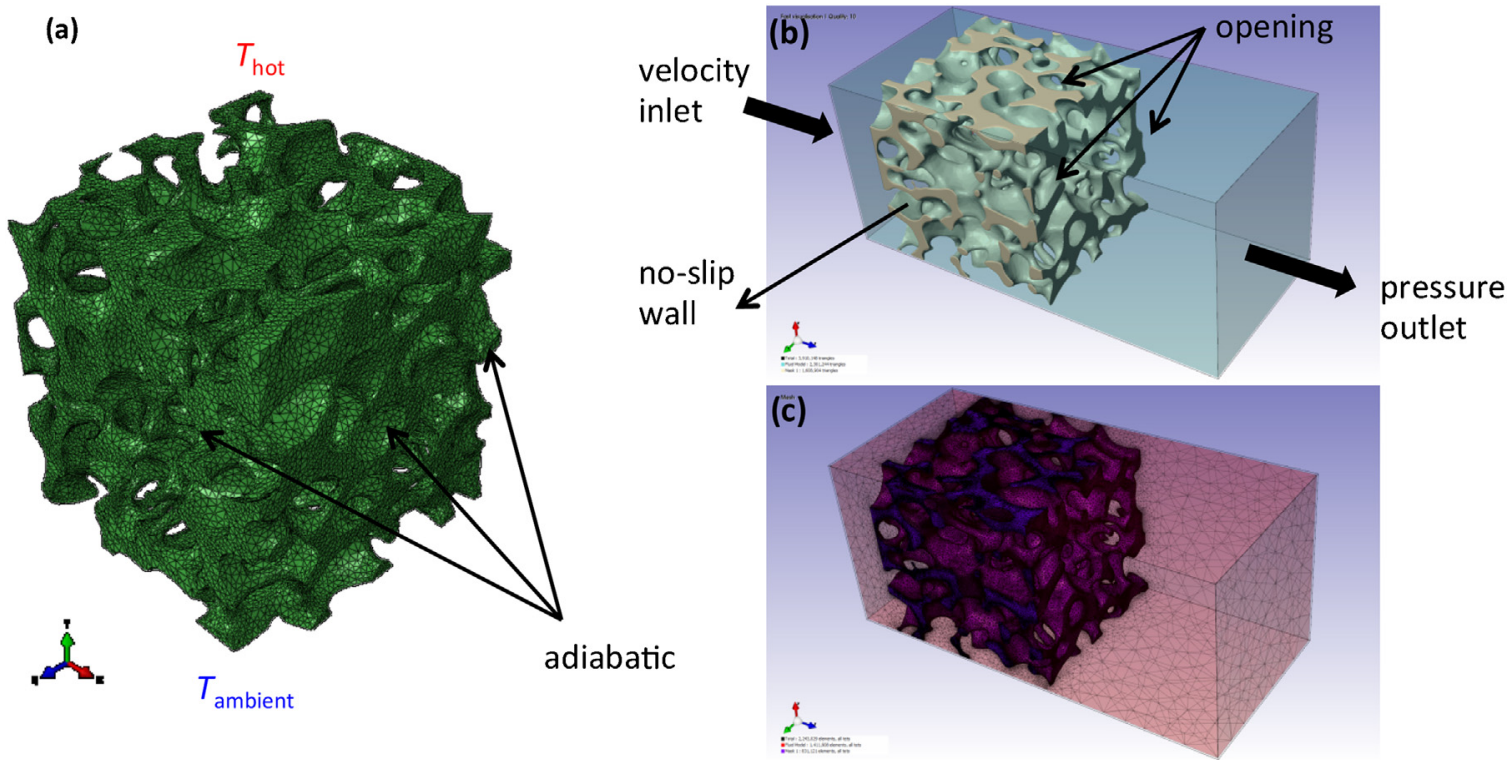

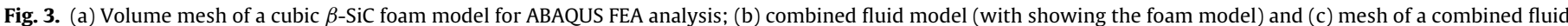
model for ANSYS CFD simulation.

temperature on the opposite surface $\left(T_{\text {ambient }}\right)$; heat conduction through the porous foams with saturating fluids in pore regions; insulated boundary conditions for all other edges or surfaces without a temperature. Three types of simulations were performed, i.e., simulations of heat conduction in vacuum with atmospheric with heat radiation (intrinsic case), heat conduction through foams with air in pore regions (dry case) and heat conduction with water as static saturating fluid in pore regions (wet case). The solid properties of $\beta$-SiC are: $\rho=1400 \mathrm{~kg} \mathrm{~m}^{-3}$, thermal conductivity $\lambda \beta_{\text {-SiC }}=120 \mathrm{~W} \mathrm{~m}^{-1} \mathrm{~K}^{-1}$, specific heat $c_{\mathrm{p}}=750 \mathrm{~J} \mathrm{~kg}^{-1} \mathrm{~K}^{-1}$ and emissivity $e=0.8$. In simulations, all the solid properties of $\beta$-SiC are treated as constants and independent of temperature.

The fluid flow analysis in $\beta$-SiC foams was performed using ANSYS FLUENT (v. 14.0). The CFD models are case-specific and only laminar flow conditions with air were used for simulation. The governing equations for mathematical modelling are continuity equation (Eq. (3)), conservation of mass) and Navier-Stokes equations (Eq. (4)) conservation of momentum) for incompressible Newtonian fluids.

$\nabla \times u=0$

$(u \times \nabla) u=-\frac{\nabla P}{\rho}+\nabla \times(v \times \nabla u)$

where $\rho$ is the fluid density, $v$ is fluid kinematic viscosity, $u$ is the flow velocity and $P$ is the pressure.

The boundary conditions used for the steady-state fluid flow simulation through foam structures are as follows (Fig. 3b): a pressure outlet boundary condition is employed at the outlet; a velocity inlet boundary condition is employed at the inlet (normal to the inlet); no-slip wall (zero velocity of the fluid on the solid surface) is applied to the walls of the struts and; opening boundary conditions are imposed on the lateral boundaries allowing the fluid to cross the boundary surface in either direction. For the velocity inlet, a fully developed flow assumption is not made because we assume that geometric model is cut out from the central part of pipe flow. Three initial velocities $\left(u_{0}\right)$, i.e., $0.0125,0.05$ and $0.2 \mathrm{~m} \mathrm{~s}^{-1}$, were used for steady-state CFD calculation with three geometrical sub-models.

\section{Results and discussion}

\subsection{FEA analysis of heat conduction through $\beta$-SiC open-cell foams}

Heat conduction simulations were performed for the cubic foam models $(10 \times 10 \times 10 \mathrm{~mm}$, Fig. $3 \mathrm{a})$. The boundary condition with a constant temperature of $400 \mathrm{~K}$ was applied to one of the surfaces of a cubic model, while room temperature ( $298 \mathrm{~K}$ ) was imposed on the opposite surface (Fig. 3a). The temperature contours in one model for the dry case (with air in the pore regions) and wet case (with water in the pore regions) are shown in Fig. 4 (this simulation was done for 3 different cubic foam models to check reproducibility). As expected, the presence of water in pores improves heat conduction through $\beta$-SiC open-cell foams. For the purpose of quantifying heat conduction through foam models, the effective static thermal conductivity (considering conduction through both the solid and pore region), $\lambda_{\text {eff }}$, was determined using Eq. (5) [34].

$\lambda_{\text {eff }}=-\frac{\int \vec{q} \times d S}{\left(\frac{\partial T}{\partial x}\right) \times S}$

where $d S$ is the outward pointing area vector and $(\partial T / \partial x)$ is temperature gradient across the two ends of a cubic foam model in the direction of $x$.

In order to evaluate the directional dependence of the computed $\lambda_{\text {eff }}$ values of simulated foam models, heat conduction simulations were performed with the prescribed high temperature on six different faces of the foam models. The corresponding $\lambda_{\text {eff }}$ values of the three cubic foam models for the two simulation cases with air and water in pore regions are summarised in Fig. 5a. Variations of $\lambda_{\text {eff }}$ values along six space directions (i.e., $\pm x, \pm y$ and $\pm z$ directions) were noticed for all the simulated cases, ranging from 4 to $23 \%$. Such local anisotropic feature of heat conduction through porous media was also reported for copper foam [38], and can be attributed to the difference in strut paths and numbers of pores along different directions within the computational domain.

The average value of $\lambda_{\text {eff }}$ for a cubic foam model $\left(\lambda_{\text {eff,ave }}\right)$ was determined by averaging $\lambda_{\text {eff }}$ values over the six $x, y$ and $z$ directions. The average effective thermal conductivity for the three models and different simulation cases are summarised in Table 1. 

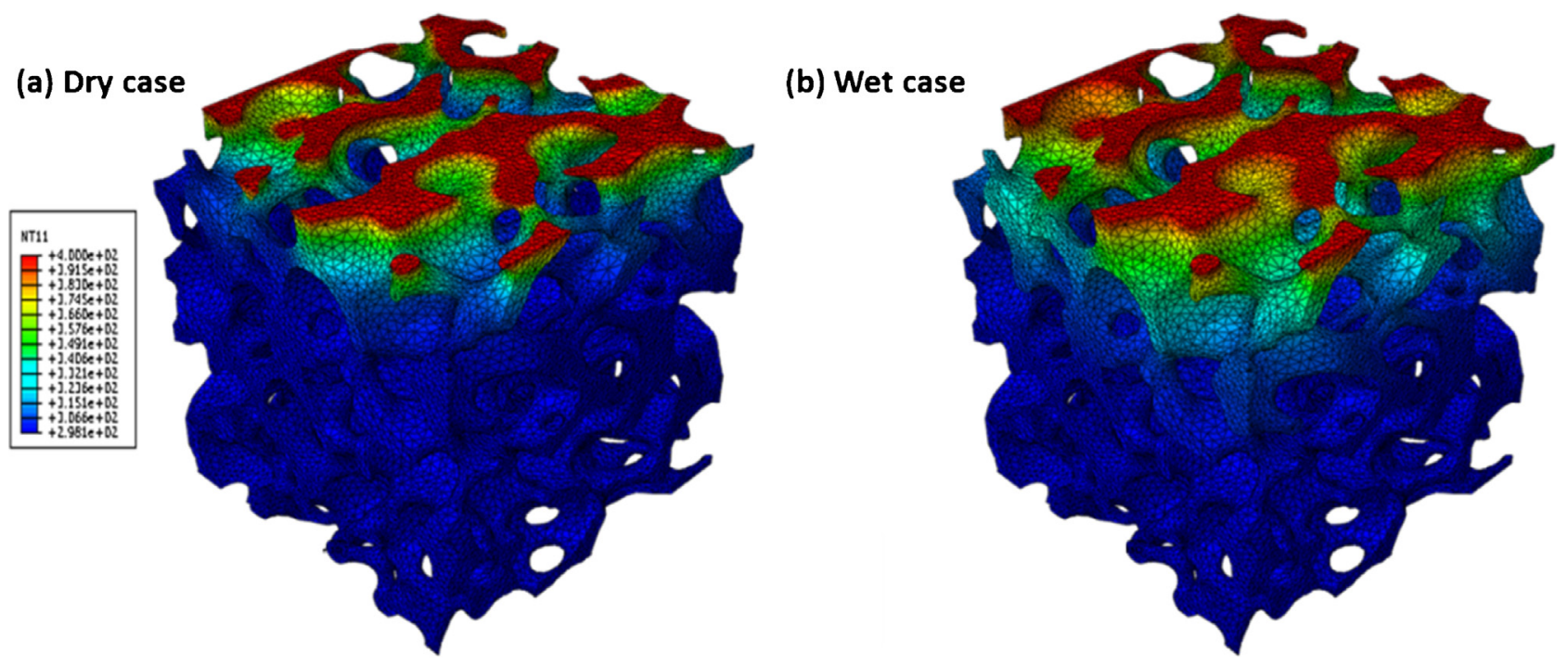

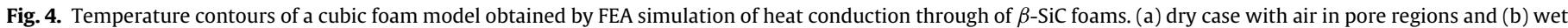
case with water in pore regions.

(a)

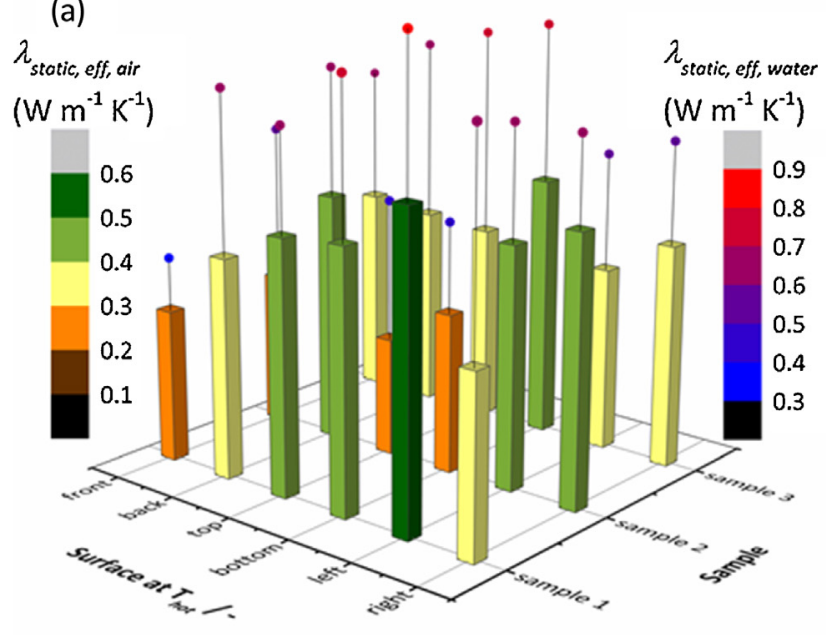

(b)

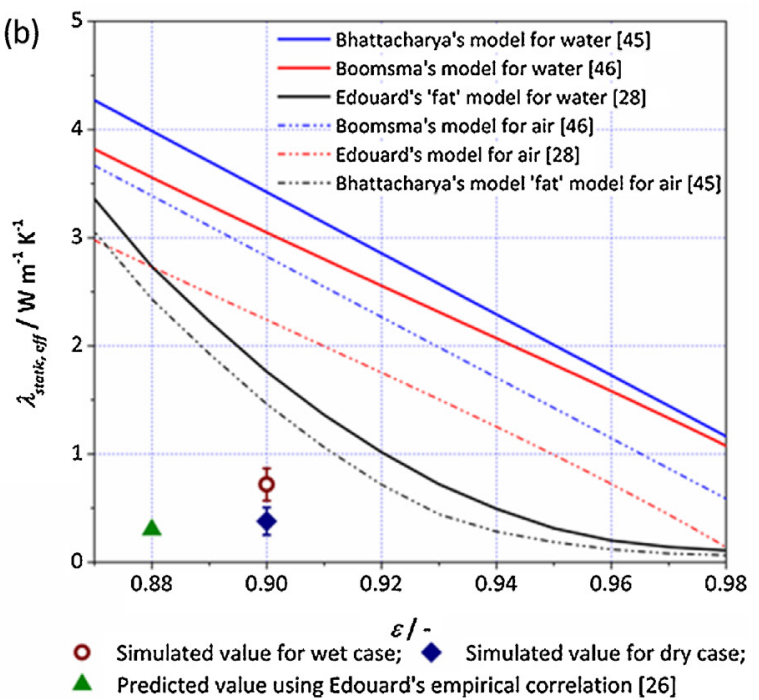

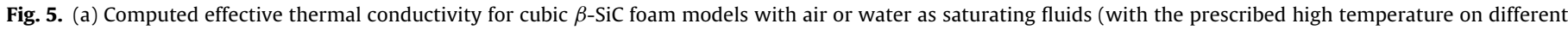

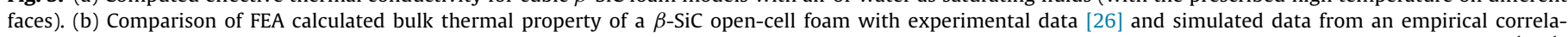

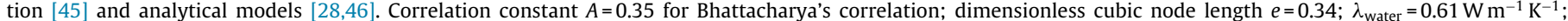
$\lambda_{\text {air }}=0.027 \mathrm{~W} \mathrm{~m}^{-1} \mathrm{~K}^{-1}$.

Table 1

Average effective thermal conductivity for different cubic $\beta$-SiC foam models and simulation cases.

\begin{tabular}{|c|c|c|c|c|c|}
\hline & \multicolumn{3}{|c|}{$\lambda_{\text {eff,ave }} / \mathrm{W} \mathrm{m}^{-1} \mathrm{~K}^{-1}$} & \multirow[t]{2}{*}{ Standard deviation (s.d.) } & \multirow{2}{*}{ Mean of $\lambda_{\text {eff,ave }}$} \\
\hline & Model01 & Model02 & Model03 & & \\
\hline Intrinsic case & 0.40 & 0.35 & 0.36 & 0.025 & 0.37 \\
\hline Dry case & 0.41 & 0.35 & 0.38 & 0.027 & 0.38 \\
\hline Wet case & 0.65 & 0.56 & 0.64 & 0.049 & 0.62 \\
\hline
\end{tabular}

As one can see, for the three cubic models from different regions of a $30 \mathrm{ppi} \beta$-SiC foam, the calculated $\lambda_{\text {eff,ave }}$ values in the simulation case are very close, with small standard deviations (s.d., was determined with regards to the cubic foam models, i.e., after averaging out all the calculated $\lambda_{\text {eff }}$ values). It suggests that the global thermal property of the bulk $\beta$-SiC open-cell foam is homogeneous making such foam materials suitable for heat transfer applications.

The means of $\lambda_{\text {eff,ave }}$ (by averaging out the $\lambda_{\text {eff,ave }}$ values for three cubic foam models) can be treated as the bulk property of a $\beta$-SiC open-cell foam disk under the scenario condition since the cubic models were selected from different regions of a $\beta$-SiC open-cell foam. By comparing the means of $\lambda_{\text {eff,ave }}$ for the three simulation cases (Table 1 ), one can see that the presence of air in pore regions in a $\beta$-SiC foam has a marginal effect on enhancing the effective static thermal conductivity, i.e., a $3 \%$ increase in the mean of $\lambda_{\text {eff,ave }}$. This result indicates that the overall effective heat conduction through $\beta$-SiC open-cell foam depends mainly on heat conductivity of the solid strut if the solid-to-fluid conductivity ratio is high (ca. 3000 
for porous $\beta$-SiC-air system). Saturating the pore region with water is equivalent to a decrease in the solid-to-fluid conductivity ratio to 130 results in an increase in the overall effective heat conduction of a $\beta$-SiC open-cell foam from 0.37 to $0.62 \mathrm{~W} \mathrm{~m}^{-1} \mathrm{~K}^{-1}$ (ca. a $70 \%$ increase in the mean of $\lambda_{\text {eff,ave }}$ ). Therefore, current heat transfer simulations suggest that systems with $\beta$-SiC foams and liquids are suitable for operating multiphase reactions with high exothermic nature for homogenising the catalyst surface temperature and preventing local hot spots formation. Such support-fluid effect was demonstrated in the case of a $\mathrm{Co} / \mathrm{Al}_{2} \mathrm{O}_{3}-\beta$-SiC foam-catalysed Fischer-Tropsch synthesis under severe reaction conditions, i.e., high CO conversion with the increased amount of liquid products [47].

The results of effective thermal conductivity from direct simulations (means of $\lambda_{\text {eff,ave }}$ ) were also compared with empirical correlations and analytical models available in the literature, such as Bhattacharya's correlation [45], Boomsma's model [46] and Edouard's 'fat' model [28], as shown in Fig. 5b. The Bhattacharya's empirical correlation was developed based on a model consisting of a 2D array of hexagonal cells representing the open-cell structure [45]. Two limiting boundaries were considered in this correlation, contributing to the overall effective thermal conductivity of opencell foams, i.e., the upper limit with the solid and liquid phases arranged in parallel to the direction of heat flow path; the lower limit with the two phases arranged in series. The two analytical models from Boomsma et al. [46] and Edouard [28] were developed based on the tetrakaidecahedron cells and perfect regular pentagonal dodecahedrons, respectively.

In Fig. 5b, the empirical correlation and analytical models clearly show the tendency to overestimate the effective thermal conductivity of a $\beta$-SiC foam disk $(\varepsilon=0.9)$ with either air or water, as compared with direct numerical simulations. With the assumption of matter accumulation at the strut connections, Edouard's 'fat' model [28] produced the closest values to the ones from FEA simulation of realistic foam structures. However, they are still about three times higher than the values determined by FEA simulations. This may be because, in comparison with realistic foam models, ones based on perfect unit cells possess the regular structure and lack of percolation points (i.e., very narrow structures through which heat conduction is drastically reduced). However, those are better represented in a realistic foam model and accounted for in the direct numeral simulations. The experimental value of effective thermal conductivity (ca. $0.27 \mathrm{~W} \mathrm{~m}^{-1} \mathrm{~K}^{-1}$, based on $\beta$-SiC foam and air system with $\varepsilon=0.88$ ) [26] has the same order of magnitude as the one determined by FEA calculation $\left(0.379 \mathrm{~W} \mathrm{~m}^{-1} \mathrm{~K}^{-1}\right)$. This result implies that direct simulations of models based on realistic porous materials are desirable to capture the intrinsic properties of the porous materials for thermal transport.

\subsection{CFD simulation of steady-state laminar flow through $\beta$-SiC open-cell foams}

CFD calculation showed that the open-cell foams contract the fluid domain, thus leading to the increase in fluid velocity within the foam models, as shown in Fig. 6 and Table 2. Fig. 6 illustrates the variation of normalised average velocities (area-weighted values, $u^{*}=u / u_{0}$ ) along the normalised length of a simulation domain ( $z$ direction). The velocities of fluids flowing through the foams were enhanced by $c a$. $60 \%$, which was obtained by comparing the means of $u^{*}$ to their according initial inlet velocities, $u_{0}$. The variation of $u^{*}$ across a cubic foam model was marginal with small standard deviations (Table 2 ), suggesting very narrow distribution of velocities. $u^{*}$ was also found to depend less on the inlet velocity with an average $7 \%$ increase by increasing inlet velocity from $0.0125 \mathrm{~m} \mathrm{~s}^{-1}$ to $0.2 \mathrm{~m} \mathrm{~s}^{-1}$, corresponding to the $u_{0}$ increase of $1500 \%$. Such characteristics of open-cell foams are advantageous

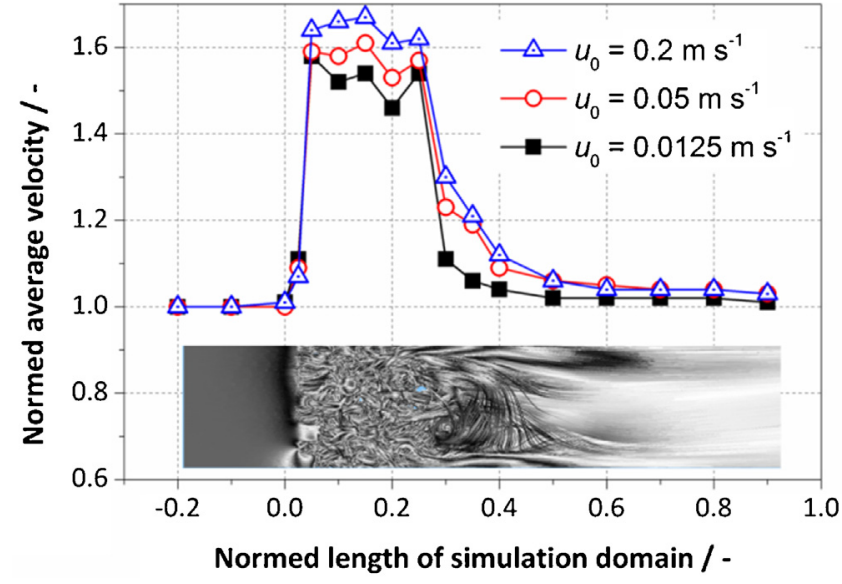

Fig. 6. Normalised area-weighted average velocities along the normed length of a simulation domain ( $z$ direction).

for running catalytic reactions since variations in the flow-rate will not affect the flow filed in foams, leading to the near-steady-state conditions for continuous-flow processes.

According to the calculated values of the pore-scale Reynolds number $\left(\mathrm{Re}_{\mathrm{p}}\right.$, in Table 2$)$, the flow fields established by the current simulation campaign are in the laminar Darcy-Forchheimer regime [48]. In order to investigate the flow features within/after the open-cell foams, surface velocity vectors on the $x z$ plans (the plane parallel to the flow direction) of different simulation cases were visualised, see Fig. 7.

Surface velocity vectors on an $x z$ plane $(y=-4 \mathrm{~mm})$ in the model 03 are shown in Fig. 7a. At $\operatorname{Re}_{\mathrm{p}}=2$ and 10, the flow fields inside the pores are clearly in the Darcy regime $\left(\operatorname{Re}_{\mathrm{p}}<38\right)$ [48]. featuring the gradual velocity variation from the maximum value to zero toward the pore walls with a parabolic velocity profile across the pores. This behavior can be explained by the dominance of the viscous force over the inertial force in Darcy regime $[36,48]$. Such dissipative viscous mechanism is similar to that observed for laminar flow in the open-cell structures of idealised foams [36] and Kelvin cells [29].

At $\operatorname{Re}_{\mathrm{p}}=40$, the flow is still laminar for each cubic foam model, but a clear anisotropy in the bulk of the flow within pores can be observed (Fig. 7a and b). This arises from the increasing effects of inertia of fluid on the flow fields inside the simulation domains, which are based on the realistic foam models. The velocity fields shown in Fig. $7 \mathrm{~b}$ are generally in Forchheimer regime $\left(38<\operatorname{Re}_{\mathrm{p}}<192\right)$ [48] that is featured with uniform distribution of velocity across the pores of foams, i.e., the maximum velocity is not located along the central path of pores. In this regime, the viscous forces are not negligible, but the influence of inertia on the velocity field increases thanks to the presence of the solid matrix. Due to mixing of high inertia flow streams coming from adjacent pores and viscous flows in the stagnation regions (pore walls), the distortion of velocity profile in the flow regions is promoted significantly.

Such flow features cannot be observed in CFD simulation of idealised periodic structures, such as the cubic lattice, the Kelvin cell and the diamond structure [31]. Stagnant regions with zero velocity are also clearly identified for all flow fields in either Darcy or Forchheimer regimes. However, the stagnant regions in Darcy regime are mainly at the pore walls, while in Forchheimer regime stagnation regions have been reduced with the velocity profiles of high gradients across the stagnant regions, indicating the less effective viscous forces compared to the inertial forces in Forchheimer regime.

Under the conditions of current CFD simulations, during the transition from the laminar Darcy regime to Forchheimer regime, 
Table 2

Normalised area-weighted average velocities and average pore-scale Reynolds number for cubic $\beta$-SiC foam models with different velocity boundary conditions.

\begin{tabular}{|c|c|c|c|c|c|c|}
\hline & \multicolumn{2}{|c|}{$u_{0}=0.0125 \mathrm{~m} \mathrm{~s}^{-1}$} & \multicolumn{2}{|c|}{$u_{0}=0.05 \mathrm{~m} \mathrm{~s}^{-1}$} & \multicolumn{2}{|c|}{$u_{0}=0.2 \mathrm{~m} \mathrm{~s}^{-1}$} \\
\hline & $u^{*}$ & s.d. & $u^{*}$ & s.d. & $u^{*}$ & s.d. \\
\hline Model 01 & 1.51 & 0.05 & 1.54 & 0.07 & 1.59 & 0.09 \\
\hline Model 02 & 1.57 & 0.06 & 1.63 & 0.06 & 1.69 & 0.08 \\
\hline Model 03 & 1.53 & 0.05 & 1.57 & 0.03 & 1.64 & 0.02 \\
\hline Mean of $u^{* a}$ & 1.54 & 0.03 & 1.58 & 0.05 & 1.64 & 0.05 \\
\hline Average $\operatorname{Re}_{\mathrm{p}}{ }^{\mathrm{b}}$ & 2 & & 10 & & 40 & \\
\hline
\end{tabular}

a A mean of $u^{*}$ was calculated by averaging out the $u^{*}$ values of three cubic foam models with same $u_{0}$.

b $\mathrm{Re}_{\mathrm{p}}$ is the pore-scale Reynolds number that is determined using the average pore diameter of $\beta$-SiC open-cell foams as the characteristic length.

(a)

$$
\begin{aligned}
& \text { Model } 03 \\
& \operatorname{Re}_{\mathrm{p}}=2 \\
& y=-4 \mathrm{~mm}
\end{aligned}
$$

Surface vectors
$6.73 \mathrm{e}-002$
$5.04 \mathrm{e}-002$
$3.36 \mathrm{e}-002$
$1.68 \mathrm{e}-002$
$0.00 \mathrm{e}+000$

$\left[\mathrm{m} \mathrm{s}^{\wedge}-1\right]$

(b)

\section{Model 01 \\ $\operatorname{Re}_{\mathrm{p}}=40$ \\ $y=-4 \mathrm{~mm}$}

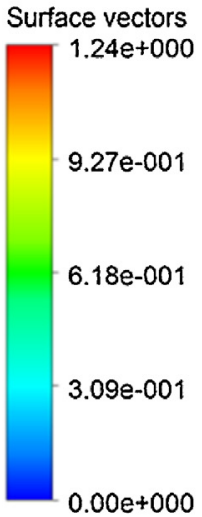

$\left[\mathrm{m} \mathrm{s} \mathrm{s}^{\wedge}-1\right]$
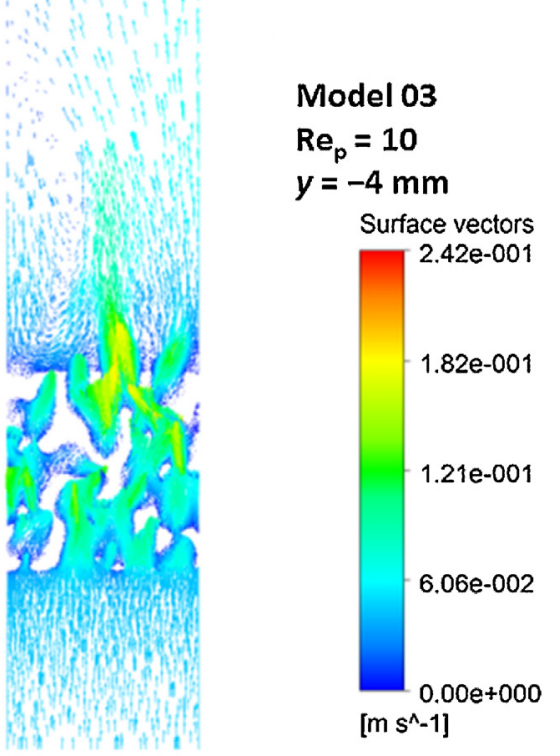

\section{Model 02 \\ $\mathrm{Re}_{\mathrm{p}}=40$ \\ $y=-2 \mathrm{~mm}$}

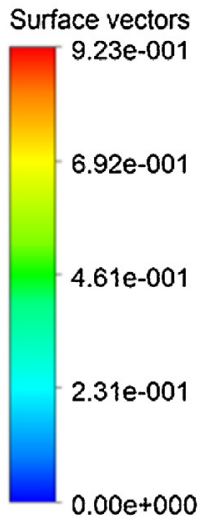

$\left[m s^{\wedge}-1\right]$
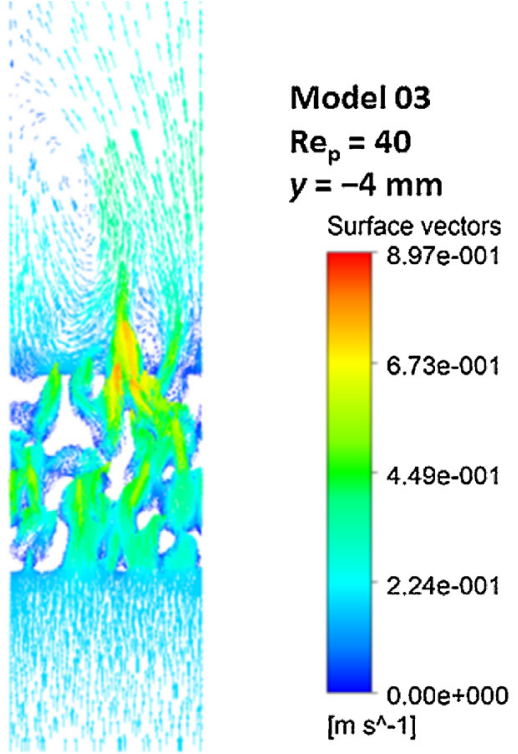

$\left[\mathrm{m} \mathrm{s}^{\wedge}-1\right]$

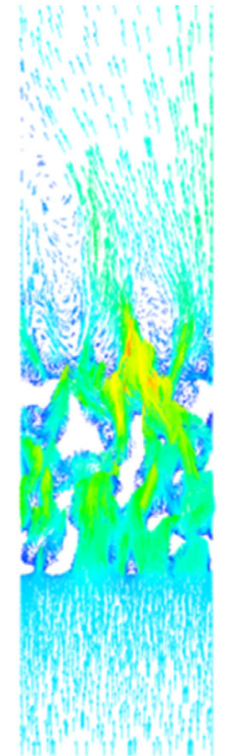

\section{Model 03 \\ $\mathrm{Re}_{\mathrm{p}}=40$ \\ $y=-2 \mathrm{~mm}$}

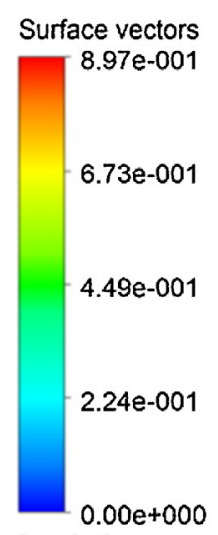

$\left[m s^{\wedge}-1\right]$
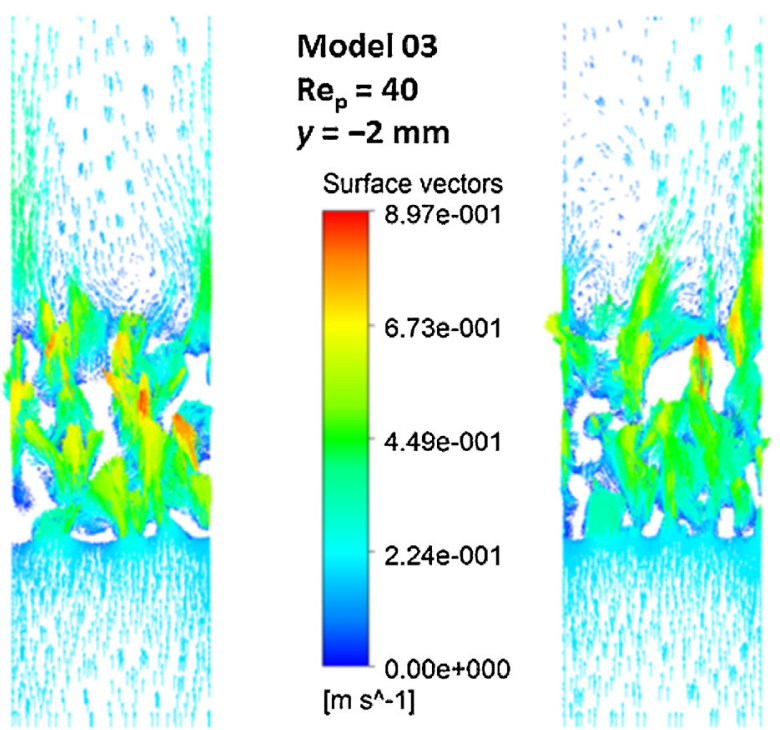

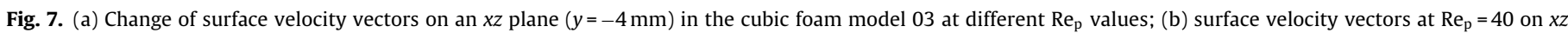
planes of three simulation domains.

the inertial contribution to the velocity field distribution was enhanced due to the presence of solid matrix. However, no eddies were generated in the flow fields within the porous structures of open-cell foams. On the other hand, circulation of fluid in the downstream regions was represented by the CFD simulation of realistic foam models. This phenomenon can be attributed to the negative pressure at the exit of foam models (Fig. 8), which increases the adverse pressure gradient on the leeward side, slow down the out- going fluid and eventually cause deformation of flow after foams, even at low $\mathrm{Re}_{\mathrm{p}}$ values. Furthermore, for the laminar flow through an open-cell foam, the inertial contribution to the pressure drop, which is related to the changes in the direction of the flow stream due to the presence of the solid matrix, can be clearly distinguished by comparing the simulated pressure distributions along a simulation domain for Darcy regime $\left(\operatorname{Re}_{\mathrm{p}}=2\right)$ and Forchheimer regime $\left(\operatorname{Re}_{\mathrm{p}}=40\right)$. 

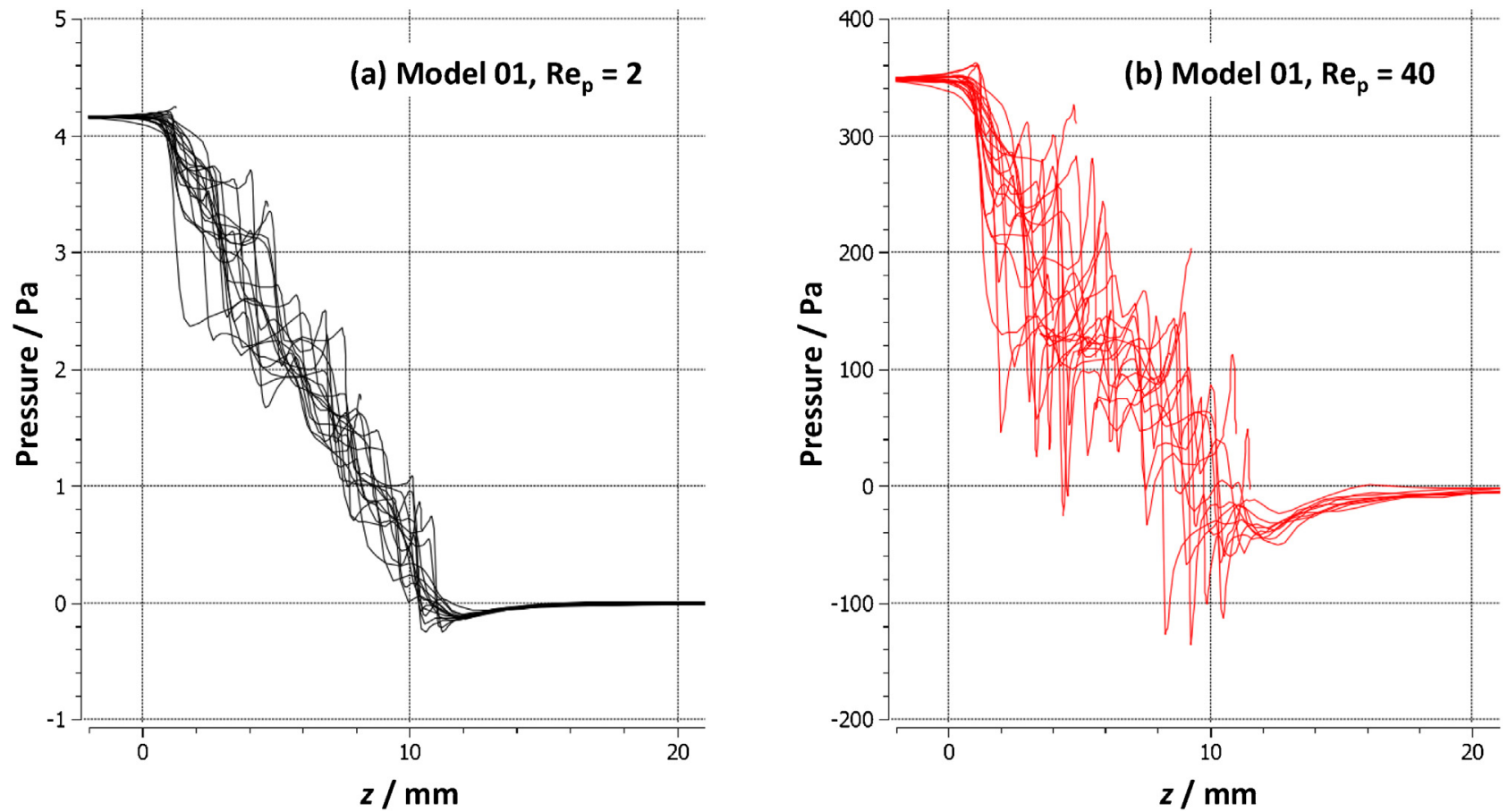

Fig. 8. Pressure distributions (along the $z$ direction) for a $30 \mathrm{ppi} \beta$-SiC foam cubic model at different flow regimes.

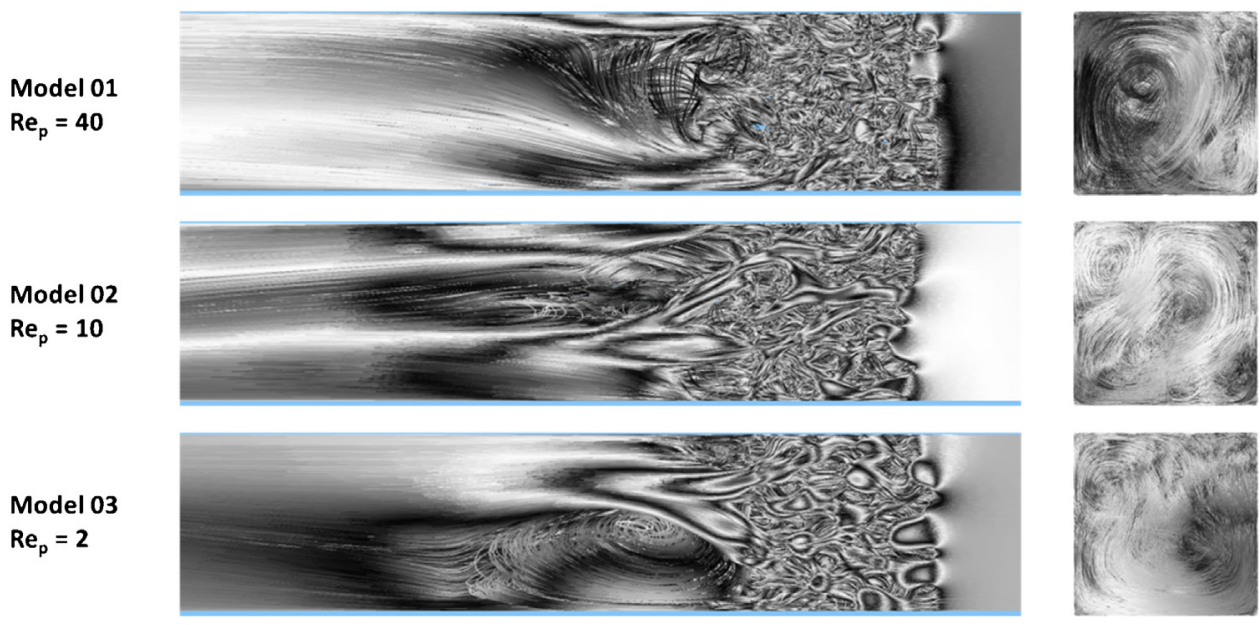

Fig. 9. Flow streamlines on $y z$ planes and $x y$ planes (normal to the flow direction) for different simulation cases showing fluid mixing after foams.

For illustration purposes, a comparison of the flow streamlines at different simulation conditions, for the three cubic foam models, is reported in Fig. 9. As it can be seen, complex flow patterns are induced by the presence of the foam, leading to both axial and radial dispersion of species in and after the open-cell foam structures.

In order to evaluate diffusion and dispersion within the flow through open-cell foams, a Matlab code was developed for analysing the data from CFD calculations by tracking the fluid particles as a function of time. 100 tracked particles on streamlines passing through a $2 \mathrm{~mm}$ circle at the entry to a simulation domain were sampled and analysed, as shown in Fig. 10. The time-independent laminar flow regime with an initial inlet velocity of $0.2 \mathrm{~m} \mathrm{~s}^{-1}$ was considered. Fig. 10a shows evolution of 100 streamlines passing through a $2 \mathrm{~mm}$ circle at the entry to a cubic foam model. Observe significant dispersion of fluid particles in streamwise direction. After $0.03 \mathrm{~s}$, the tracked particles were found dispersed well along the flow direction, i.e., $z$ direction. Diffusion of the tracked particles on $x y$ plane is shown in Fig. 10b. Observe the significant lateral dispersion of the fluid particles.

Fig. 11 shows distributions of the displacement of a fluid particle in $x, y$, and $z$ directions in linear and logarithmic scales. It should be noted that dispersion of the axial $z$ displacement significantly exceeds that in transverse $x$ and $y$ directions. In the $x$ and $y$ distributions, the peak width at half height is in agreement with that suggested by the random walk model: 30 ppi corresponds to 12 pores per the length of the $10 \mathrm{~mm}$ sample which suggests the distribution half-width of $25.4 \mathrm{~mm} / 30 \times \sqrt{12} \approx 3 \mathrm{~mm}$. For the actual flow velocity of $c a .0 .33 \mathrm{~m} \mathrm{~s}^{-1}$ within a foam model at $\operatorname{Re}_{\mathrm{p}}=40$ this corresponds to diffusion constant and thermal diffusivity of $2.6 \times 10^{-4} \mathrm{~m}^{2} \mathrm{~s}^{-1}$ which by far exceeds the values of molecular diffusion $\left(10^{-5} \mathrm{~m}^{2} \mathrm{~s}^{-1}\right)$.

The microscopic phenomena rendered by the CFD simulation of realistic foam models demonstrate the advantages of employing open-foam structures for enhancing the mass transfer-limited reactions under laminar flow conditions. However, the nature of 

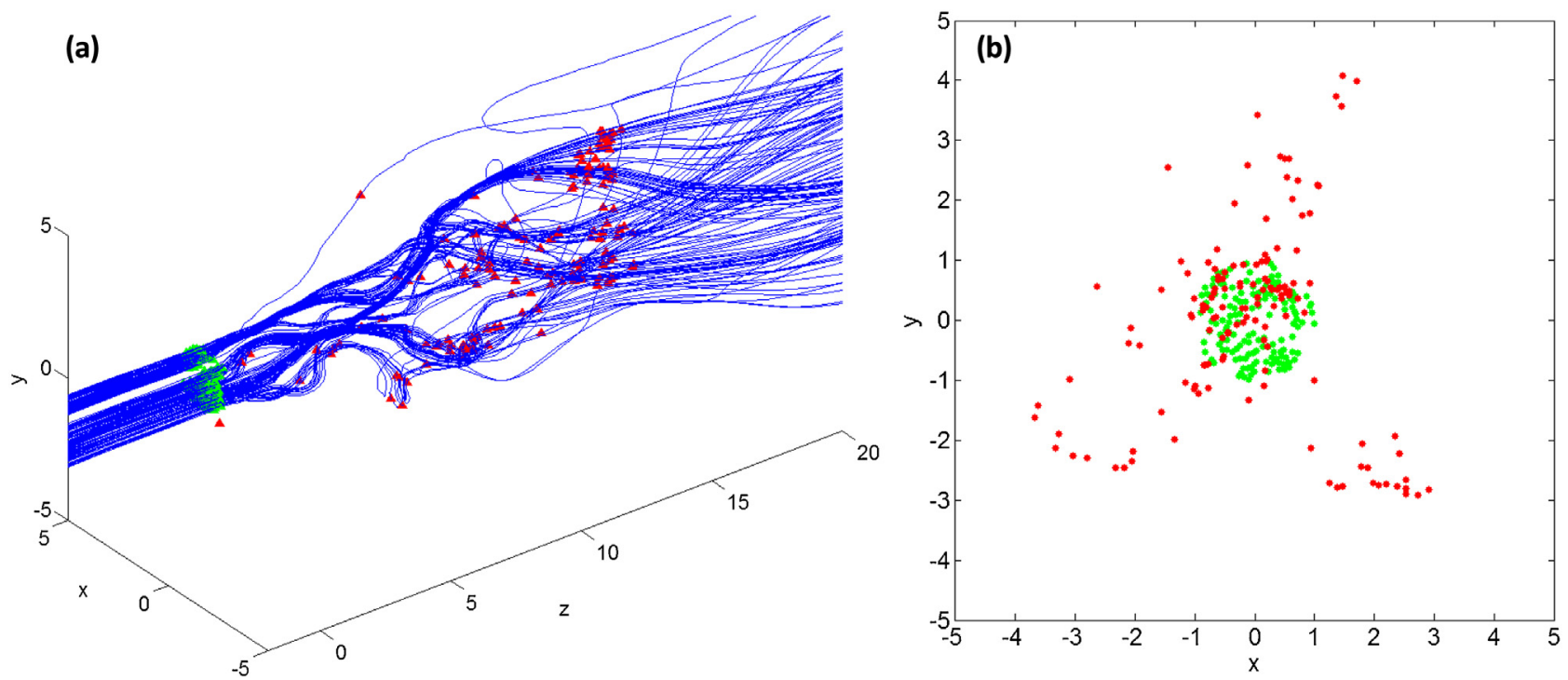

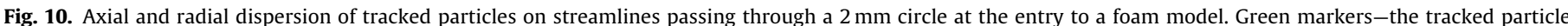

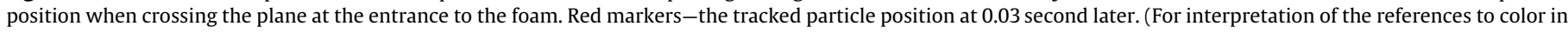
this figure legend, the reader is referred to the web version of this article.)
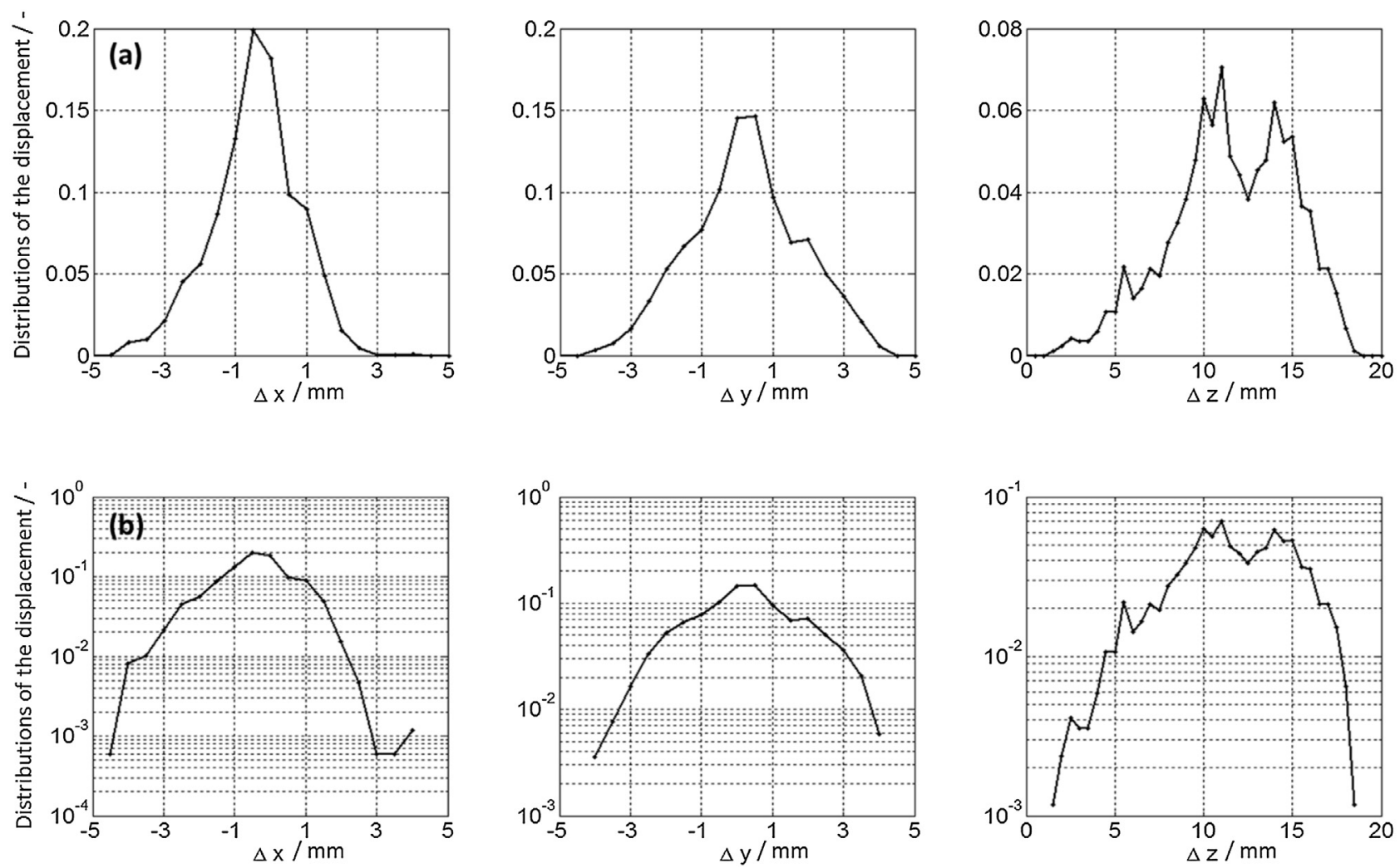

Fig. 11. Distributions of the displacement of a fluid particle in $x, y$, and $z$ directions. (a) in linear scale and (b) in logarithmic scale.

species transport still needs to be interpreted in the framework of dispersion theories. Detailed analysis of the final distance between fluid particles with different initial distance between the particles is currently underway.

\section{Conclusions}

Microtomography-based modelling of $\beta$-SiC open-cell foams was performed in this work. The structural features of three $30 \mathrm{ppi}$ foam samples were well represented in the realistic 3D geometrical models through high-resolution X-ray microtomography. Accurate pore-scale simulations, FEA and CFD, were carried out to evaluate the heat transfer and fluid flow characteristics through $\beta$-SiC foams.

The FEA simulation of heat conduction revealed that the overall effective heat conduction through $\beta$-SiC open-cell foams depends on the solid to fluid conductivity ratio. By decreasing the ratio by one magnitude from 3000 ( $\beta$-SiC and air system) to 130 ( $\beta$-SiC and water system), the heat conduction was increased by $c a$. $70 \%$ sug- 
gesting that systems with $\beta$-SiC foams and liquids are suitable for operating multiphase reactions with high exothermic/endothermic nature for homogenising the catalyst surface temperature.

The predicted results from the thermal simulation of realistic foam models were compared with ones from empirical correlation, analytical models and experimental measurement. It was found that models based on perfect unit cells tend to overestimate the heat conduction through porous media. While the FEA simulation based on realistic foam models produced comparable results (in terms of the effective thermal conductivity) to the one determined by experimental measurement (i.e., $0.379 \mathrm{~W} \mathrm{~m}^{-1} \mathrm{~K}^{-1}$ versus $\left.0.27 \mathrm{~W} \mathrm{~m}^{-1} \mathrm{~K}^{-1}\right)$. This result demonstrates that microtomographybased modelling of cellular materials can reserve the detailed geometrical features of real materials and hence capture their intrinsic thermal properties, which will benefit the model-aided process design based on foams.

Fluid flow CFD simulations through foams were performed at laminar regimes with air. Simulation results showed that the anisotropic feature of realistic foam models promotes the axial and radial mixing of fluids (within or after foams) that is ideal for carrying out catalytic reactions where enhanced mass transfers are desirable. The diffusion coefficient of flows within foams was estimated as in the magnitude of $10^{-4} \mathrm{~m}^{2} \mathrm{~s}^{-1}$ that is one order of magnitude higher than the molecular values for laminar flows in channel configurations. 3D approach (model generation, meshing and simulation) based on the X-ray computed microtomography technique, although challenging, can be a promising approach for helping the design and optimisation of catalytic processes based on open-cell foams, especially if coupled with a realistic description of chemical reaction kinetics.

An important consequence of the enhanced lateral diffusion is the increase in lateral heat conductivity. Indeed, lateral diffusivity, induced by the flow, provides the thermal diffusivity of the same value of $2.6 \times 10^{-4} \mathrm{~m}^{2} \mathrm{~s}^{-1}$. This corresponds to the thermal conductivity of $\left(2.6 \times 10^{-4}\right) \rho c_{\mathrm{p}}$ which is approximately $1000 \mathrm{~W} \mathrm{~m}^{-1} \mathrm{~K}^{-1}$. This by orders of magnitude exceeds the molecular thermal conductivity suggesting the latter one can be neglected in simulations.

\section{Acknowledgements}

This work was supported by the European Community's Seventh Framework Programme [FP7/2007-2013] under project "FREECATS", project reference 280658. XF thanks the pump priming project of the School of Chemical Engineering and Analytical Science (CEAS), The University of Manchester. XO is grateful to the Guangzhou Elite Project scholarship and the CEAS postgraduate research scholarship, The University of Manchester. FX thanks the China Scholarship Council (CSC) for supporting him as a CSC visiting scholar at The University of Manchester (201308350040).

\section{References}

[1] X. Fan, M. Manchon Gonzalez, W. Karen, S.R. Tennison, A. Kozynchenko, P.K. Plucinski, A.A. Lapkin, Coupling of heck and hydrogenation reactions in a continuous compact reactor, J. Catal. 267 (2009) 114-120.

[2] E. Tronconi, G. Groppi, C.G. Visconti, Structured catalysts for non-adiabatic applications, Curr. Opin. Chem. Eng. 5 (2014) 55-67.

[3] X. Fan, V. Sans, S.K. Sharma, P.K. Plucinski, V.A. Zaikovskii, K. Wilson, S.R. Tennison, A. Kozynchenko, A.A. Lapkin, Pd/C catalysts based on synthetic carbons with bi- and tri-modal pore-size distribution: applications in flow chemistry, Catal. Sci. Technol. (2016), http://dx.doi.org/10.1039/C5CY01401H.

[4] Y. Jiao, C. Jiang, Z. Yang, J. Zhang, Controllable synthesis of ZSM-5 coatings on SiC foam support for MTP application, Microporous Mesoporous Mater. 162 (2012) 152-158

[5] P. Nguyen, C. Pham, Innovative porous SiC-based materials: from nanoscopic understandings to tunable carriers serving catalytic needs, Appl. Catal. A: Gen. 391 (2011) 443-454

[6] Innovative $\beta$-silicon carbide catalyst support solutions. Availabe from: http:// www.sicatcatalyst.com/. (accessed 12.10.15.).
[7] X.H. Han, Q. Wang, Y.G. Park, C. T’Joen, A. Sommer, A. Jacobi, A review of metal foam and metal matrix composites for heat exchangers and heat sinks, Heat Transfer Eng. 33 (2012) 991-1009.

[8] M. Lacroix, P. Nguyen, D. Schweich, C. Pham Huu, S. Savin-Poncet, D. Edouard, Pressure drop measurements and modeling on SiC foams, Chem. Eng. Sci. 62 (2007) 3259-3267.

[9] Y. Liu, S. Podila, D.L. Nguyen, D. Edouard, P. Nguyen, C. Pham, M.J. Ledoux, C. Pham-Huu, Methanol dehydration to dimethyl ether in a platelet milli-reactor filled with H-ZSM5/SiC foam catalyst, Appl. Catal. A: Gen. 409 (2011) 113-121.

[10] Y. Liu, D. Edouard, D.L. Nguyen, D. Begin, P. Nguyen, C. Pham, C. Pham-Huu, High performance structured platelet milli-reactor filled with supported cobalt open cell $\mathrm{SiC}$ foam catalyst for the Fischer-Tropsch synthesis, Chem. Eng. J. 222 (2013) 265-273.

[11] S. Ivanova, B. Louis, B. Madani, J.P. Tessonnier, M.J. Ledoux, C. Pham-Huu, ZSM-5 coatings on $\beta$-SiC monoliths: possible new structured catalyst for the methanol-to-olefins process, J. Phys. Chem. C 111 (2007) 4368-4374.

[12] M.M. Elamin, O. Muraza, Z. Malaibari, H. Ba, J.-M. Nhut, C. Pham-Huu, Microwave assisted growth of SAPO-34 on $\beta$-SiC foams for methanol dehydration to dimethyl ether, Chem. Eng. J. 274 (2015) 113-122.

[13] Y. Jiao, C. Jiang, Z. Yang, J. Liu, J. Zhang, Synthesis of highly accessible ZSM-5 coatings on SiC foam support for MTP reaction, Microporous Mesoporous Mater. 181 (2013) 201-207.

[14] Y. Liu, B. de Tymowski, F. Vigneron, I. Florea, O. Ersen, C. Meny, P. Nguyen, C. Pham, F. Luck, C. Pham-Huu, Titania-decorated silicon carbide-containing cobalt catalyst for Fischer-Tropsch synthesis, ACS Catal. 3 (2013) 393-404.

[15] L. Truong-Phuoc, T. Truong-Huu, L. Nguyen-Dinh, W. Baaziz, T. Romero, D. Edouard, D. Begin, I. Janowska, C. Pham-Huu, Silicon carbide foam decorated with carbon nanofibers as catalytic stirrer in liquid-phase hydrogenation reactions, Appl. Catal. A: Gen. 469 (2014) 81-88.

[16] H. Ba, Y. Liu, X. Mu, W.-H. Doh, J.-M. Nhut, P. Granger, C. Pham-Huu, Macroscopic nanodiamonds/ $\beta$-SiC composite as metal-free catalysts for steam-free dehydrogenation of ethylbenzene to styrene, Appl. Catal. A: Gen. 499 (2015) 217-226.

[17] N.A. Kouamé, D. Robert, V. Keller, N. Keller, C. Pham, P. Nguyen, TiO2/beta-SiC foam-structured photoreactor for continuous wastewater treatment, Environ. Sci. Pollut. Res. 19 (2012) 3727-3734

[18] N.A. Kouamé, D. Robert, V. Keller, N. Keller, C. Pham, P. Nguyen, Preliminary study of the use of $\beta$-SiC foam as a photocatalytic support for water treatment, Catal. Today 161 (2011) 3-7.

[19] A.N. Kouamé, R. Masson, D. Robert, N. Keller, V. Keller, $\beta$-SiC foams as a promising structured photocatalytic support for water and air detoxification, Catal. Today 209 (2013) 13-20.

[20] D. Edouard, M. Lacroix, C. Pham-Huu, Pressure drop modeling on SOLID foam: state-of-the art correlation, Chem. Eng. J. 144 (2008) 299-311

[21] D. Edouard, S. Ivanova, M. Lacroix, E. Vanhaecke, C. Pham, C. Pham-Huu, Pressure drop measurements and hydrodynamic model description of $\mathrm{SiC}$ foam composites decorated with SiC nanofiber, Catal. Today 141 (2009) 403-408.

[22] J. Ahmed, C. Pham-Huu, D. Edouard, A predictive model based on tortuosity for pressure drop estimation in 'slim' and 'fat' foams, Chem. Eng. Sci. 66 (2011) 4771-4779

[23] D. Edouard, M. Lacroix, C. Pham, M. Mbodji, C. Pham-Huu, Experimental measurements and multiphase flow models in solid SiC foam beds, AIChE J. 54 (2008) 2823-2832.

[24] M. Saber, T.T. Huu, C. Pham-Huu, D. Edouard, Residence time distribution, axial liquid dispersion and dynamic-static liquid mass transfer in trickle flow reactor containing $\beta$-SiC open-cell foams, Chem. Eng. J. 185-186 (2012) $294-299$.

[25] T.T. Huu, R. Philippe, P. Nguyen, D. Edouard, D. Schweich, Radial dispersion in liquid upflow through solid SiC foams, Ind. Eng. Chem. Res. 50 (2011) 4329-4334.

[26] D. Edouard, T.T. Huu, C. Pham-Huu, F. Luck, D. Schweich, The effective therma properties of solid foam beds: experimental and estimated temperature profiles, Int. J. Heat Mass Transfer 53 (2010) 3807-3816.

[27] T.T. Huu, M. Lacroix, C. Pham-Huu, D. Schweich, D. Edouard, Towards a more realistic modeling of solid foam: use of the pentagonal dodecahedron geometry, Chem. Eng. Sci. 64 (2009) 5131-5142.

[28] D. Edouard, The effective thermal conductivity for slim and fat foams, AIChE J 57 (2011) 1646-1651.

[29] T. Horneber, C. Rauh, A. Delgado, Fluid dynamic characterisation of porous solids in catalytic fixed-bed reactors, Microporous Mesoporous Mater. 154 (2012) 170-174

[30] J. Klostermann, R. Schwarze, C. Brücker, Meshing of porous foam structures on the micro-scale, Eng. Comput. 29 (2013) 95-110.

[31] T. Horneber, C. Rauh, A. Delgado, Numerical simulations of fluid dynamics in carrier structures for catalysis: characterization and need for optimization, Chem. Eng. Sci. 117 (2014) 229-238.

[32] A.S. Suleiman, N. Dukhan, Forced convection inside metal foam: simulation over a long domain and analytical validation, Int. J. Therm. Sci. 86 (2014) 104-114.

[33] A.S. Suleiman, N. Dukhan, Long-domain simulation of flow in open-cell mesoporous metal foam and direct comparison to experiment, Microporous Mesoporous Mater. 196 (2014) 104-114.

[34] K.K. Bodla, J.Y. Murthy, S.V. Garimella, Microtomography-based simulation of transport through open-cell metal foams, Numer. Heat Transfer A: Appl. 58 (2010) 527-544. 
[35] K.K. Bodla, J.Y. Murthy, S.V. Garimella, Resistance network-based thermal conductivity model for metal foams, Comput. Mater. Sci. 50 (2010) 622-632.

[36] A. Della Torre, G. Montenegro, G.R. Tabor, M.L. Wears, CFD characterization of flow regimes inside open cell foam substrates, Int. J. Heat Fluid Flow 50 (2014) 72-82

[37] P. Ranut, E. Nobile, L. Mancini, High resolution microtomography-based CFD simulation of flow and heat transfer in aluminum metal foams, Appl. Therm. Eng. 69 (2014) 230-240.

[38] K.K. Bodla, J.Y. Murthy, S.V. Garimella, Direct simulation of thermal transport through sintered wick microstructures, J. Heat Transfer 134 (2012) 012602.

[39] T. Fiedler, I.V. Belova, G.E. Murch, Critical analysis of the experimental determination of the thermal resistance of metal foams, Int. J. Heat Mass Transfer 55 (2012) 4415-4420.

[40] J. Kumar, A. Attridge, P.K.C. Wood, M.A. Williams, Analysis of the effect of cone-beam geometry and test object configuration on the measurement accuracy of a computed tomography scanner used for dimensional measurement, Meas. Sci. Technol. 22 (2011) 035105

[41] J. Kumar, A. Attridge, P.K.C. Wood, M.A. Williams, Analysis of the effect of cone-beam geometry and test object configuration on the measurement accuracy of a computed tomography scanner used for dimensional measurement, Meas. Sci. Technol. 22 (2011) 035105.
[42] J. Kumar, A.-H.G. Abulrub, A. Attridge, M.A. Williams, Effect of X-Ray computed tomography scanning parameters on the estimated porosity of foam specimens, in: 2nd IEE E International Conference on Mechanical, Industrial, and Manufacturing Technologies (MIMT 2011), Singapore, 2011.

[43] ScanIP, +FE, +NURBS and +CAD Reference Guide for SIMPLEWARE 5.1, 2012

[44] A.E. Green, P.M. Naghdi, A general theory of an elastic-plastic continuum, Arch. Ration. Mech. Anal. 18 (1965) 251-281.

[45] A. Bhattacharya, V.V. Calmidi, R.L. Mahajan, Thermophysical properties of high porosity metal foams, Int. J. Heat Mass Transfer 45 (2002) 1017-1031.

[46] K. Boomsma, D. Poulikakos, On the effective thermal conductivity of a three-dimensionally structured fluid-saturated metal foam, Int. J. Heat Mass Transfer 44 (2001) 827-836.

[47] M. Lacroix, L. Dreibine, B. de Tymowski, F. Vigneron, D. Edouard, D. Bégin, P. Nguyen, C. Pham, S. Savin-Poncet, F. Luck, M.-J. Ledoux, C. Pham-Huu, Silicon carbide foam composite containing cobalt as a highly selective and re-usable Fischer-Tropsch synthesis catalyst, Appl. Catal. A: Gen. 397 (2011) 62-72.

[48] N. Dukhan, Metal Foams: Fundamentals and Applications, DEStech Publications, Inc., Pennsylvania, 2012. 